\title{
Regulation for chronic disease control: the pathfinder role of tobacco
}

\section{Andrew Penman}

The Cancer Council NSW

Email: andrewp@nswcc.org.au

\begin{abstract}
Regulation for health in the modern era has its foundations in the English Public Health Act of 1848. Early legislation was concerned with controlling environmental causes of disease. However, the focus on regulation today within health departments has diminished, displaced by a focus on services and related programs. The regulatory debate is now centred on what degree of protection, or safety margin, is required, and how regulatory efficiency may be improved. The example of tobacco control is reviewed to show how regulation can play a large role in chronic disease control, and consideration given to how regulatory tools could be further diversified and regulatory effectiveness improved.
\end{abstract}

Regulation for health in the modern era has its foundations in the English Public Health Act of 1848 and the imprint of this legislation can still be found in legislation of most jurisdictions formerly under the British Empire. The miasma theory of disease was then accepted wisdom and legislation was concerned with controlling environmental causes of disease and conferring the powers required to do so. Public Health Acts have retained their focus on health protection, i.e. on controlling the microbial, physical, toxic and xenobiotic causes of disease.

Containing the potential for these hazards to cause disease remains essential, but the regulatory debate focuses around how great a degree of protection, or safety margin, is required and how regulatory efficiency may be improved. Functions integral to early boards of health, such as building regulation, have been spun off to other agencies. In consequence, the focus within health departments on the regulatory craft has diminished, displaced by a focus on health services and related programs.
Population health goals in the early 21 st century mostly focus on reducing mortality from chronic disease and the compression of associated morbidity. ${ }^{1}$ These conditions share common proximate risk factors rooted in lifestyle. Health promotion developed largely to change lifestyle behaviours through education and social change - a change mediated though information, services, the built environment and organisational practice. In this paradigm, the role of health protection, or health regulation, has been minimised, and the title given to the frontline warrior of the first public health act - Inspector of Public Nuisances seems out of place in these more egalitarian times.

\section{Developments in health regulation}

Health promotion has resulted in a more explicit understanding of the diversity of the health environment and recognition that individual behaviour is profoundly affected by social context. Human behaviour and the environment interact, and environmental regulation can play an important role in chronic disease control. This understanding has required an evolution in the philosophy and practice of health regulation. The story of tobacco control illustrates the role that regulation can play in modifying behaviours and lifestyles.

One development is in our understanding of chronic disease. Traditional health protection excelled at elimination of a hazardous agent at source. In chronic disease, specific regulatory measures are crafted to eliminate not the proximate cause of disease, but any of a number of contributory causes. Taken as a whole, these measures may be demonstrably effective in reducing risk, but the contribution of any single measure may be moderate to minor. Advertising bans, tax increases, smoke-free public places, on-pack warnings and point-of-sale restrictions have all contributed to smoking abatement. Although evidence can be adduced to demonstrate short-term impact on behaviour, it is more difficult to isolate the impact of each measure on smoking prevalence, and especially to predict this in advance of a regulatory decision. ${ }^{2}$ The statement, "Why don't you just ban the stuff?", heard in popular discourse on tobacco illustrates the public expectation that our measures should be more decisively effective.

Another development has been to recruit regulatory instruments from outside the health sector, appropriate to the environmental-behavioural goals. In tobacco control, taxing 
powers - state tobacco licensing fees and now federal excise - have been imposed at unprecedented levels to raise the cost of tobacco dramatically, well beyond the level needed to fund the treatment of the health consequences of smoking. Price remains one of the most effective measures for lowering smoking and consumption rates. ${ }^{3}$

A third change has been to transfer enforceable sanctions from the person who commits a hazardous act to the person who creates the circumstances that contribute. One cannot yet be personally fined just for smoking. This is not without precedent in public health law - owners as well as occupiers are enjoined to comply with controls on dwellings - but the extent to which this has been pursued in tobacco control is extraordinary. The ban on advertising in any form includes a striking assumption of powers over broadcasting, rewriting generally accepted freedoms in communication.

Many factors have contributed to the regulatory achievements in tobacco.

1. Regulation has followed rather than led social norms.

All credit here to health advocates and communicators who have transformed social consciousness on tobacco.

2. Advocacy has deliberately undermined the credibility of the tobacco industry and its influence with government, reducing the political price that government may pay for regulation.

3. Research into tobacco and tobacco control has been critical to developing the evidence base for regulation. The Cancer Council Victoria has led the world in high quality research not only in creating the case for regulatory reform, but as importantly, also in validating the outcomes of regulation.

4. Regulation is very cost-effective. Over the long term, governments have been reluctant to spend money on health promotion strategies in tobacco. One could argue for greater spending on the implementation of regulation but governments prefer measures that are inexpensive to implement.

5. Regulation leverages the effectiveness of non-regulatory strategies. It is striking how effective Australian tobacco social marketing campaigns have been despite limited expenditure compared to that in the USA. It is likely that the absence of pro-tobacco marketing in Australia lies behind this outcome.

\section{Future tobacco legislation}

Governments have treated tobacco in an exceptional way compared to products of lesser risk, like heroin in medical practice or lead in petrol, which have been scheduled or regulated to extinction. Even though it is tempting to revert to this course as the prevalence of smoking falls, it is this exceptionalism that provides some precedent for how other risks might be regulated. There are several ways in which tobacco regulation might be extended in the future while keeping it a legal product. One important feature is that the regulations reduce commercial incentives to frustrate public health goals. All have implications for the broader control of chronic disease.

\section{Licensing}

On 22 April 2008, the New South Wales (NSW) government announced a number of reforms as part of its reform package Protecting Children from Tobacco and foreshadowed a licensing system for tobacco retailers. ${ }^{4}$ Although retailer reaction has been benign, the final proposal is for a negative licensing system, conferring the power to prohibit a business from selling tobacco if, for example, it sells to minors or displays tobacco products. A future direction for health-based licensing is to mould the retail tobacco environment actively by reducing the density of retail outlets, diminishing convenience retailing and modifying the exchange that occurs within an outlet to encourage quitting - akin to converting drug pushers into habit-management agents.

\section{Statutory liability for tobacco-related harms}

The industry mantra that tobacco is a legal product is used to absolve them from product liability. When claims have been pressed in the courts, the results have been mixed and the majority of litigants are deterred by the costs.

The Dust Diseases Act is an example of how the behaviour of business can change when the balance of power is shifted in favour of the damaged party. Tobacco smoke is a dust, and to bring tobacco-related harms within the purview of this Act is scientifically defensible. The risks of commercial loss arising from litigation for product related harm are presently too low to affect the industry's returns. The imposition of liability though statute on the industry, and the simplification of the judicial path to redress, would increase the success rate of product-related claims for damages. This in turn would introduce the real risk of business loss and seriously reframe commercial incentives to sell tobacco, legal product or not.

\section{Regulating tobacco emissions}

Direct regulation of product is a long-standing tool in environmental health. Attempts to regulate tar and nicotine content of cigarettes paradoxically amplified adverse health effects through industry manipulation of the performance characteristics of cigarettes. ${ }^{5}$ There is good evidence that cigarettes differ in hazard profile and proposals are afoot to reduce the toxicity of the combusted unit through product regulation. ${ }^{5}$ But anticipating the population impact of changes to a tobacco stick is error prone and because the industry enjoys a scientific and technical advantage over the regulator, it may again frustrate renewed attempts to regulate toxins in cigarettes. ${ }^{6}$ An alternative approach may be to take a leaf out of environmental 
regulation and license tobacco companies to pollute. This shifts the focus of regulation from the uncertainties of individual dose exposure and harms to population exposure. It could be accomplished by transforming the current excise regime into a Pareto tax imposed on cigarette emissions, weighted according to the harmfulness of specific constituents. $^{7}$ (A Pareto tax - or Pareto efficient tax - is one designed to redistribute economic allocations or outputs so as to optimise welfare. The point at which no further welfare gains can be made from further redistributions is termed the Pareto optimum.) With the imposition of penalties, the same system could be used to cap the aggregate weighted emissions delivered into the lungs of Australians and lower this cap progressively. ${ }^{8}$ While the idea of positively sanctioning commercial trade in deadly products may appal some, it has the virtue of improving on the current situation where the tobacco industry has an unfettered licence to pollute the lungs of Australians. The effect of this change would be to turn the science and product development endeavours of a powerful industry somewhat more towards meeting rather than frustrating public health goals.

\section{Compulsory acquisition of commercial information}

Information asymmetry is an impediment to evidencebased public health practice. The expenditure and efforts of health agencies and public health researchers to understand, anticipate and respond to the tobacco epidemic are puny compared to the information and research amassed by the tobacco industry. A requirement that all information on product and the market be made available to public health agencies for tobacco-control purposes could stop this cat and mouse game.

\section{Shifting the incidence of costs in tobacco control}

It seems beyond argument that the tobacco industry is the principal vector in the tobacco epidemic. However, there are other players, who wittingly or unwittingly, for profit or not, play a contributory role. For example, there is strong evidence that the glamorous portrayal of smoking in movies promotes youth smoking. At the moment, the community bears the cost of countering this effect. It is open to regulators to impose this cost on the cinema, film and television industries by requiring them to run approved anti-smoking advertisements in association with movies promoting smoking. ${ }^{9}$

A great barrier to effective regulation in chronic disease lies in the social framing of propositions for state interventions in health. Health is not alone in having a culture removed from the mainstream and seen as self-referential. The acceptance of health protection in the nineteenth and early twentieth centuries rested on a particular view of the public interest - one where the measure concerned reflected an interest in common to all members of society, or at least a preponderant proportion. The perception of an imminent common threat is a powerful motivator for regulation, providing a groundswell of support even for cost-ineffective measures.

However, with hazards that are seen to involve the personal assumption of risk - be it obesity, sedentary behaviour, smoking or drinking - this view of the public interest is unsound, and opposition frames regulatory controls as a social engineering intrusion into individual rights and freedoms. The libertarian view restricts the domain of public regulation to ensuring the provision of information only and holds the unfettered exercise of private property rights as essential to liberty.

However, as Feintuck explains, at the core of democratic values is the commitment to full participation and equal standing in society. ${ }^{10}$ To the extent that private matters limit this potential, they become matters of public interest. In a capitalist democracy, although private property rights are central to the notion of liberty, the notion rests on the belief that this maximises the welfare of the community. If the exercise of this private property power results in fundamentally undemocratic outcomes, limiting the ability of others to enjoy the entitlements of citizenship and participation, then the underlying assumption is rebutted and intervention is justified. This principle is readily accepted in trade practices, anti-trust and utilities regulation. It is a driving principle in the public funding and provision of health services, but is strangely absent as a driving philosophy of health regulation. This is even stranger, perhaps, when we reflect that Edwin Chadwick came to the role of enacting the Public Health Act of 1848 from his experience as Poor Law Commissioner. He saw health regulation as a tool to address poverty and its attendant burden. As we remake public health for the challenge of preventing chronic disease, it may be that a new philosophy of health regulation will enable us to undertake a similar journey, adapting the experience of success in tobacco to the control of other risk factors.

\section{References}

1. Fries JF. Aging, natural death and the compression of morbidity. $N$ Engl J Med 1980; 303(3): 130-5.

2. Research and Evaluation Committee, ed. Australia's National Tobacco Campaign, Evaluation Report. Volume 1 (1999). Canberra: Commonwealth Department of Health and Aged Care; 1999. Available from: http://www.quitnow.info.au/ internet/quitnow/publishing.nsf/content/evaluation-reports (Cited 3 November 2008.)

3. Ranson MK, Jha P, Chaloupka FJ, Nguyen SN. Global and regional estimates of the effectiveness and cosy-effectiveness of price increases and other tobacco control policies. Nicotine Tob Res 2002; 4(3): 311-9. doi:10.1080/14622200210141000

4. Protecting Children from Tobacco. A NSW Government Discussion Paper on the Next Steps to Reduce

Tobacco-Related Harm. North Sydney: NSW Department of Health; 2008. Available at: http://www.health.nsw.gov.au/pubs/ 
2008/pdf/protecting_children_from_tobacco.pdf (Cited 22 July 2008.)

5. Burns DM, Dybing E, Gray N, Hecht S, Anderson C, Sanner T et al. Mandated lowering of toxicants in cigarette smoke: a description of the World Health Organization TobReg proposal. Tob Control 2008; 17(2): 132-41. doi:10.1136/tc.2007.024158

6. Kozlowski LZ. The proposed tobacco regulation: the triumph of hope over experience? Tob Control 2008; 17(2): 132-41. doi:10.1136/tc.2008.025155

7. Stiglitz J. Pareto Efficient and Optimal Taxation and the New Welfare Economics. From Handbook of Public Economics. Auerbach AA, Feldstein M, editors. Amsterdam: Elsevier Science Publishers B.V.; 1987: pp. 991-1042.
8. Penman AG. Regulating combustible tobacco products when every cigarette is doing you damage. 13th World Conference on Tobacco OR Health, Washington 12-15 July 2006. Available from: http://2006.confex.com/uicc/wctoh/ techprogram/P6321.HTM (Cited 9 September 2008.)

9. Edwards C, Harris W, Cook D, Bedford K, Zuo Y. Out of the Smokescreen: does an anti-smoking advertisement affect young women's perception of smoking in movies and their intention to smoke? Tob Control 2004; 13(3): 277-82. doi:10.1136/tc.2003.005280

10. Feintuck M. The public interest in regulation. Oxford: Oxford University Press; 2004. 